ENCYCLOPEDEE Encyclopédie berbère

BERBERE

$22 \mid 2000$

22 | Hadrumetum - Hidjaba

\title{
Hammam Guergour
}

G. Camps

\section{OpenEdition}

Journals

Édition électronique

URL : http://journals.openedition.org/encyclopedieberbere/1649

DOI : 10.4000/encyclopedieberbere.1649

ISSN : 2262-7197

\section{Éditeur}

Peeters Publishers

\section{Édition imprimée}

Date de publication : 1 janvier 2000

Pagination : 3350-3352

ISBN : 2-7449-0127-X

ISSN : 1015-7344

\section{Référence électronique}

G. Camps, "Hammam Guergour », Encyclopédie berbère [En ligne], 22 | 2000, document H19, mis en ligne le 01 juin 2011, consulté le 24 septembre 2020. URL : http://journals.openedition.org/ encyclopedieberbere/1649; DOI : https://doi.org/10.4000/encyclopedieberbere.1649

Ce document a été généré automatiquement le 24 septembre 2020.

(C) Tous droits réservés 


\section{Hammam Guergour}

\section{G. Camps}

1 Le hammam Guergour, sur le Bou Sellam, est une station thermale réputée pour ses eaux sulfatées qui jaillissent à $43^{\circ}$. La ville romaine qui s'était développée auprès de ses sources portait le même nom que le Bou Sellam : Sava. De cette cité qui avait acquis le statut de municipe, subsistent des vestiges de thermes (canalisations, piscines) un mausolée et plusieurs inscriptions chrétiennes dont une memoria des martyrs Rogatianus Donatus, Garg (ilius). Il est difficile de déterminer à quelle église se rattachaient ces martyrs de Sava. En 411, comme dans de nombreuses villes africaines, deux évêques étaient en compétition à la tête de la Plebs Assabensis, le catholique Sextilius et le donatiste Marcianus. L'évangélisation de cette région semble avoir gagné une bonne partie de la population. Au cours de la semaine qu'il consacra à l'exploration du Guergour, en 1938, L. Les-chi identifia les ruines de plusieurs églises à Algrège (Aïn Degrage), à Aïn Dokoar (Lesbi), Oundedja (peut-être Ad Olivam). Il existait à Aïn Roua* (Horrea) une basilique d'où provient la remarquable vasque en pierre portant une décoration animale (serpent, scorpion, colombes, coquilles saint-Jacques) florale et géométrique. Un chrisme confirme le caractère chrétien de cette vasque sans doute destinée aux ablutions des fidèles. Tous ces éléments de décor sont sculptés en champ levé. 
Paysage du Guergour. Le village de Koudia sous la neige (photo M. Gast).

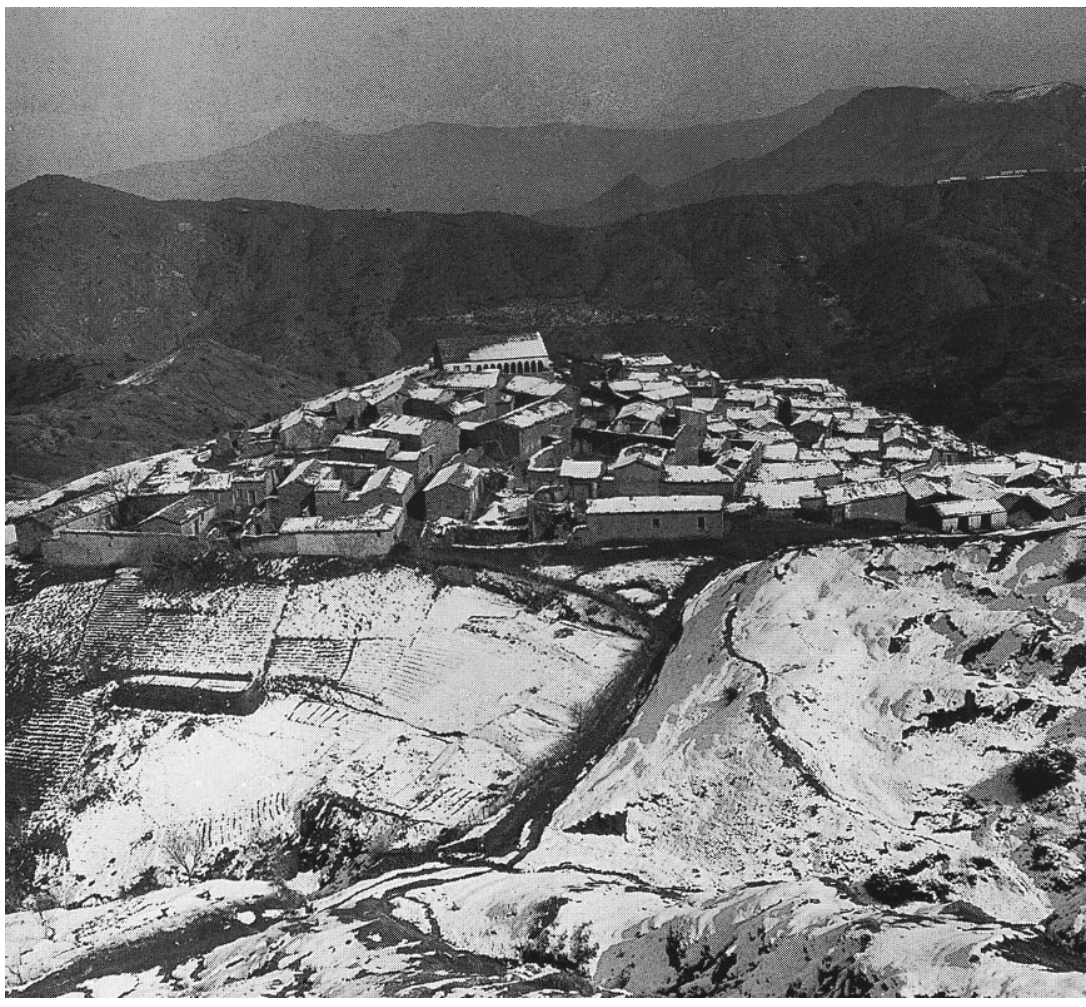

Moulin et pressoir à huile de Koubba des Beni Brahim, Guergour (photo F.E. Roubet).

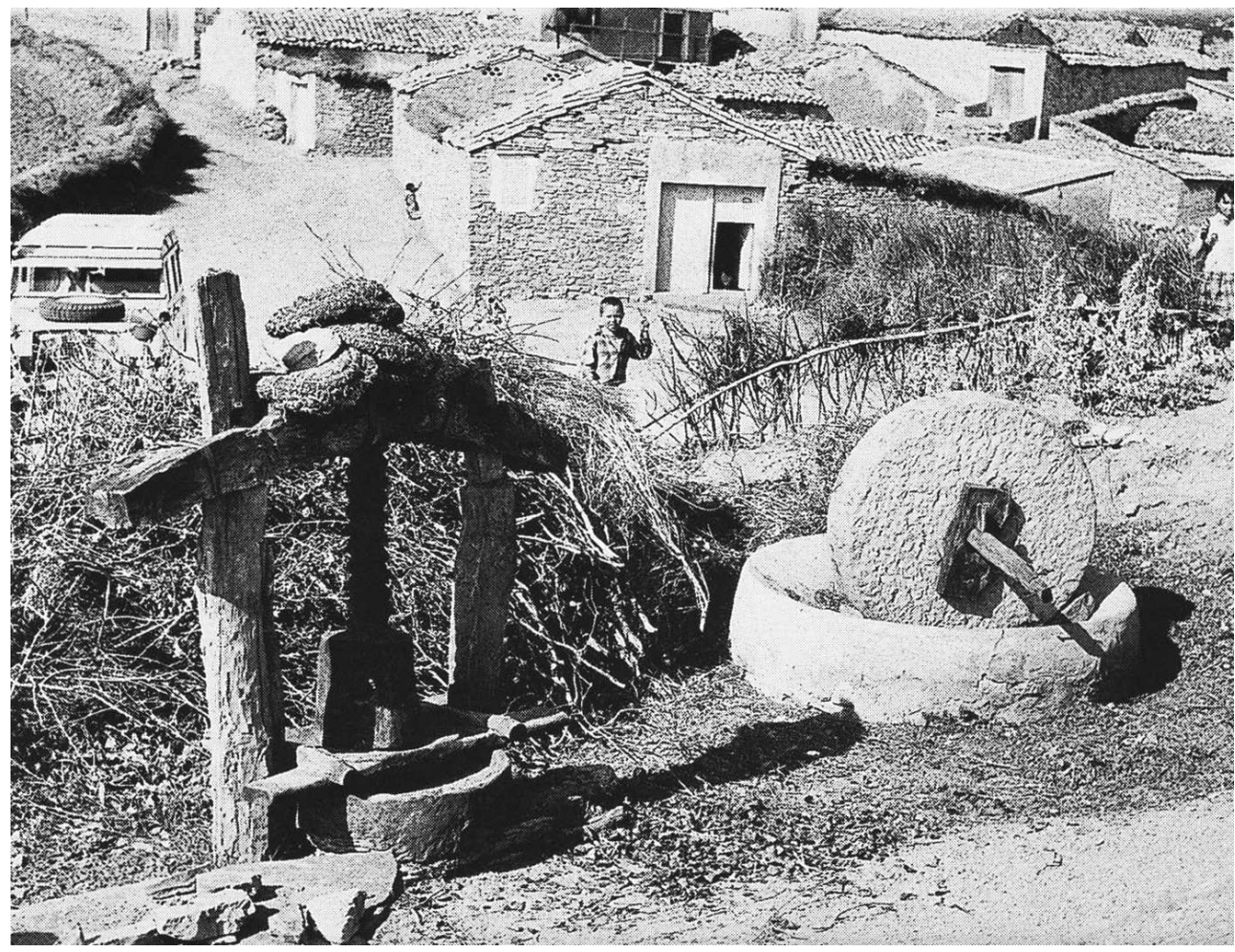

2 Située à l'ouest de la plaine sétifienne et séparée de la mer par la double chaîne du Babor* $(2004 \mathrm{~m})$ et du Tababor, la région du Guergour doit son nom au djebel Guergour qui a également donné son nom au Hammam. Le djebel Guergour appartient au système 
orographique des Biban* qui limite la région au sud. A l'ouest, la vallée de la Soumam sépare les berbérophones du cours inférieur du Bou Sellam des Kabyles du Djurdjura*. Le Bou Sellam traverse le pays suivant un trajet sud-est nord-ouest puis approximativement est-ouest pour confluer avec l'oued Sahel, devenu oued Soumam, au niveau d'Akbou.

3 Cette région au relief tourmenté fut de tout temps réputée difficile à traverser. Les vallées encaissées sont souvent réduites à des gorges étroites, comme les Portes de fer dans les Biban ou les gorges du Bou Sellam à Hammam Guergour (ex Lafayette). Les difficultés rencontrées expliquent que dès l'époque romaine les voies principales entre Maurétanie sitifienne et Maurétanie césarienne passaient soit au nord (voie littorale) soit, de préférence, au sud des Monts du Hodna et du Guergour (voie de Sitifis à Auzia). Cependant deux routes secondaires assuraient les relations, l'une entre Sitifis et Saldoe (Bejaïa/Bougie), l'autre entre Sitifis et Tubusuptu (Tiklat).

4 Le Guergour a été moins exploré que les régions voisines, ce qui fit croire que la romanisation y avait été moins développée qu'ailleurs. Il est sûr, en effet, que la région eut à souffrir du voisinage des Bavares*. Le danger qu'ils représentaient atteint son paroxysme au cours de la seconde moitié du $\mathrm{III}^{\mathrm{e}}$ siècle lorsqu'ils joignirent leurs forces à celles des Quinquegentanei de Grande Kabylie. Ces difficultés expliquent, en partie, l'absence dans la région, de cités d'une certaine importance. Celles-ci, comme Saldøe et Sitifis, se situent à la périphérie du Guergour.

Le nom de Guergour a tendance à s'étendre en dehors des limites traditionnelles car il s'applique à des tapis dont beaucoup sont tissés en dehors de la zone berbérophone de Petite Kabylie, jusqu'à Barika, à l'est du Hodna. L. Golvin a insisté, à juste titre, sur le caractère oriental très marqué de ces tapis manifestement imités des tissages turcs. De tous les tapis de l'Algérie orientale, ceux dits du Guergour sont les seuls à figurer des fleurs au naturel. Leur succès est dû autant à la qualité du tissage qu'à la richesse de leur décor polychrome.

\section{BIBLIOGRAPHIE}

GSELL S., Atlas archéologique de l'Algérie, feuille n 16, Sétif.

Id., Les Monuments antiques de l'Algérie, Paris, Challamel, 1901.

LESCHI L., “Une excursion archéologique dans le Guergour”, Bull. de la Soc. histor. et géogr. de Sétif, t. II, 1941, p. 143-167.

PIAULT M., 'Études berbères II, Le berbère dans la Commune mixte du Guergour”, Rev. Afric, t. XC, 1946, p. 203.

GOLVIN L., Les arts populaires en Algérie, t. V, Les Tapis algériens, Alger, 1955. 
INDEX

Mots-clés : Algérie, Archéologie 